\title{
Relationship among Personality Traits and Conflict Handling Styles of Call Center Representatives and Appraisal of Existing Service Model
}

\author{
Syed Shameem Ejaz ${ }^{1}$, Farah Iqbal ${ }^{1} \&$ Anjum Ara $^{1}$ \\ ${ }^{1}$ Department of psychology, University of Karachi, Karachi, Pakistan \\ Correspondence: Syed Shameem Ejaz, Department of Psychology, University of Karachi, Karachi, 75270, \\ Pakistan. E-mail: shameem.ejaz@gmail.com
}

Received: August 10, 2012

Accepted: September 10, $2012 \quad$ Online Published: November 12, 2012

doi:10.5539/ijps.v4n4p27

URL: http://dx.doi.org/10.5539/ijps.v4n4p27

\begin{abstract}
In order to identify the relationship between conflict handling styles and personality traits of call centre representatives and to extract and appraise any existing model, i.e., style of public dealing/conflict resolving, we have carried out this research. A total of 128 call centre representatives from a Bank and a Telecommunication Company have participated in the study. We assumed that for Bank and for Telecommunication Company both, the most commonly used conflict handling styles would be integrating and obliging, regardless of the personality traits of the call centre representatives and without having control on gender and age. The participants were asked to complete two scales, the big five inventory and the conflict handling style scale. Results confirm our assumptions through correlations, factor analysis, and SEM. We have found significant relationships among personality traits and conflict handling styles. Three conflict-handling styles were persistent in all statistical analyses and i.e., integrating, obliging, and compromising. However, SEM extracts the same variables in models with low regression weights and high residual variance on Neuroticism that may be indicative of depiction of trait by representatives at certain places in certain situations.
\end{abstract}

Keywords: traits, conflict-handling style, service model

\section{Introduction}

Conflicts are inevitable and even the one who researches or practices conflict handling or conflict management, faces conflicts. Therefore, everyone has to face conflicts at any point of time in life at personal as well as organizational level. Conflicts are defined as the process, which shows incompatibility or disagreement in two social entities (Rahim 2002). We can classify conflicts as positive, negative, or balanced. The positive view claims that the conflict is a force, which proves to be helpful or motivating in achieving the organizational goals (Jameson, 1999; Pelled, Eisenhardt \& Xin, 1999; Rahim, 2001, 2002, Wall \& Callister, 1995). On contrary negative view says that the conflict is a force, which does not add something useful to the organization or individual.

\subsection{Understanding Conflict}

The balancing view, states that the conflicts can be a balancing factor in any situation, and with a balanced conflict, the individual and the organization, both can take benefit out of it. In addition, this view believes that the management of the conflict should be in a way that it proves to be positive factor rather than going toward negative side. There are many theories that suggest certain ways through which conflicts can be handled.

R. R. Blake and J. S. Mouton (1964) developed the managerial grid for identifying conflict. They posit four styles of conflict handling with different levels varying from being assertive to being cooperative. These styles are smoothing, forcing withdrawal, compromising, and problem solving.

In smoothing, there is high cooperation and low assertiveness. In forcing, there is low cooperation and high assertiveness. The Withdrawal, sometimes referred as traditional style, incorporates low cooperation and low assertiveness. The compromise, is a situation that balances the cooperation and assertiveness. While the problem solving, involves high cooperation and high assertiveness. All of these styles represent a situation in which any one of the parties is either winning or losing except for the problem solving style that poses a situation where both the parties emerge as a winner. 
Rahim (1983, 2001) categorizes these styles in five dimensions as integrating, obliging, dominating, avoiding, and compromising. Integrating, includes openness and exchange of ideas and an attempt to resolve every issue. Obliging, is satisfying others and focusing on commonalities. Dominating, is enforcing thoughts on to others. Avoiding, is merely escaping the conflicting situation. Compromising, is to forgo something in order to achieve the desired results by both entities.

The relationships of personal traits (extraversion and agreeableness), conflict-handling styles, and functional/dysfunctional conflicts are examined from a sample of facility managers in Hong Kong by using Rahim's conflict style model and the Big Five personality traits of extraversion and agreeableness. In this study, extraversion shows positive correlation with the integrating and compromising styles, which are conducive to functional conflict incidents. The integrating style is the most commonly adopted style among facility managers in Hong Kong (Liu, A. \& Zhai, X. 2011).

Rahim M. A., Antonioni D., Psenicka C. (2001) studied five French and Raven bases of supervisory power (coercive, reward, legitimate, expert, and referent), styles of handling conflict with supervisor (problem solving and bargaining), and job performance. The structural equation modeling indicates that legitimate power influenced referent power positively and coercive power negatively, and reward and legitimate powers positively influenced expert power, which in turn, positively influenced referent power. Referent power, in turn, positively influenced problem solving (i.e., using more integrating and less avoiding styles) and negatively influenced bargaining (i.e., using more dominating and less obliging styles) conflict-management styles, and finally, problem solving style, but not bargaining style, positively influenced job performance.

\subsection{CRM and Call Centers}

Businesspersons, from ancient times, try to resolve conflicts quickly to enhance their relationship with customers thus evolving the concept of Customer Relationship Management (CRM). A good CRM provides; quality and efficiency, decrease in overall costs, decision support, enterprise-ability, customer Attentions, increase profitability, improved planning, and improved product development. World Wide Web as a phenomenon happening to us inculcated expectations for rapid response from a provider whenever a need arises at the user end, and this end user is not necessarily generating the demand from within the boundaries of the producer, this may be global call.

In our scenario, the action from a customer (end user) is not always generated for placing a purchase order; most of the time they require some sort of information about product, services, or if they are having difficulty handling or mantling or configuring a product. This has given rise to the concept of call centers; these centers guide a global customer toward the solution of her or his problems. This strategy helps maintaining the expected rapidity of the response, which is necessary to keep the customer database alive with returning customers who feel satisfaction. Researches show that $72 \%$ of the customers returned to service provider if their complaints were resolved however, $46 \%$ never returned in the absence of a prompt response on their complaints (Stone 1999).

Primarily call centers function in six classified categories; Customer Service -function of a customer service center is to provide assistance regarding a company's or organization's products or services. Telesales - function of a sales center is primarily to generate revenue through the sale of the company's goods and services through inbound calls, outbound calls or both. Technical Support - function of these centers is to provide assistance in using a customer's products. Dispatch - function of a dispatch center is to take an inbound call and in turn engage a resource to address the problem or customer need. Collections - function of these centers to contact customers with the primary purpose of collecting money or funds. Research - function of a research center is not to sell or support a product but to conduct research for the company or outside organization.

People who work in call centers carry the corporate image (Evenson, Harker, \& Frei, 1999). They feel tremendous pressure, because they should be prompt in providing solution and information and guidance and for all of these they must be very well aware of the services and products of the company and above all they must sound empathetic and cooperative and energetic. The attitude toward customer and the knowledge about the product is highly essential in building good customer relations.

Askin, Armony, and Vijay; discussed the importance of behavioral issues associated with both call center agents and customers, and to the interface between call center operations and sales and marketing, in their paper in 2009.

In their study in 2009, Olukemi, Shanthi, Sijun, found that all personality factors except extraversion/introversion, as well as locus of control were significantly related to one or more of the performance measures.

Call center representatives require cultivating some social skills like communication, listening, conflict resolution, problem solving, and stress and anger management. Although some individuals are good enough naturally to 
handle situations that arise in call centers however, others require proper training to acquire these skills. Earlier, technology was considered as the only factor that affects the performance of the call centers, however, these days social skills are the most sought characteristics in a call center representative. Call centers that are working as per human needs and not by the technological excellence are more successful.

Suitability of call center representatives legitimately depends on their personality characteristics or traits, because most of the required social skills in these representatives are associated to personality traits. A trait like extroversion is a commonly understandable thing and any two individuals can be evaluated based on this common trait. Understanding the personality and relating call center representation to personality traits requires a taxonomical framework of personality. The most common taxonomy is the Big-Five-Model of personality characteristics. This model is hierarchical in nature and classifies personality in five broad facet and each bipolar facet (factor) helps more in identifying specific details.

We have designed this research study to investigate the styles to handle conflict situations in Pakistani call centers. Two types of inbound call centre representatives one; belonging to the banking sector, and another; call center representatives belonging to telecommunications sector, were selected, as they are the most frequently utilized sectors in Pakistan.

\section{Methodology}

\subsection{Participants}

The data for this research was collected from a total of 128 participants who were call center agents. The participants worked in two sectors, Banks $(\mathrm{N}=65)$ and Telecommunication $(\mathrm{N}=63)$. There was no discrimination among the male and female participants, only that they worked in call centers. The participants were included in the study just because they were call centre agents, so we can say that purpose sampling was done in this study.

\subsection{Material}

We have several scales for conducting a personality research on traits however, we used the John \& Srivastava's Big Five Inventory (44 items) and Rahim's conflict handling scale (to find out the conflict handling style) because of its relative shortness.

\subsection{Big Five Inventory (John \& Srivastava, 1999)}

The Big Five Inventory (BFI) is a self-report inventory designed to measure the Big Five dimensions. It is quite brief for a multidimensional personality inventory and consists of short phrases with relatively accessible vocabulary. It takes around 5 minutes to complete. The standard BFI (John \& Srivastava, 1999) consists of 44 short-phrase items, rated on a five-step scale ranging from $1 \mathrm{D}$ "disagree strongly" to $5 \mathrm{D}$ "agree strongly".

Validity \& reliability. The internal consistency reliability, factor structure, and convergent-discriminant validity of the Italian translation of the Big Five Inventory (BFI) were assessed in two independent samples of nonclinical adult volunteers (Sample 1: $\mathrm{N}=500$; Sample 2: $\mathrm{N}=316$ ) and in one sample of adolescent volunteers (Sample 3: $\mathrm{N}$ $=223$ ). Two adult subsamples ( $\mathrm{n}=70$, and $\mathrm{n}=141$, respectively) also provided 2 -month retest reliability data. The internal consistency reliabilities were adequate for all five BFI scales (mean $\alpha$ values were $.77, .78$, and .81 for Sample 1, Sample 2, and Sample 3, respectively); all test-retest correlations were greater than .75 in both adult participant subsamples.. The BFI scales showed adequate convergent-discriminant validity coefficients. These findings suggest that the BFI is a succinct measure of the Big Five personality traits and it provides satisfactory reliability and validity data (Fossati, Borroni, Marchione \& Maffei, 2011)

\subsection{Conflict Handling Inventory (Rahim, 1983)}

Validity \& reliability. Confirmatory factor analysis of data (from 5 samples, $\mathrm{n}=84$ full-time employed management students; $\mathrm{n}=550$ public administrators; $\mathrm{n}=214$ university administrators; $\mathrm{n}=250$ bank managers and employees in Bangladesh; and $\mathrm{n}=578$ managers and employees) on the 28 items of the Rahim Organizational Conflict Inventory-II were performed The results provided support for the convergent and discriminant validities of the subscales measuring the 5 styles of handling interpersonal conflict (integrating, obliging, dominating, avoiding, and compromising) ( Rahim \& Magner, 1995). The scale was revalidated and an item total correlation was carried out with inter-item correlation estimate ranging from 0.30 to 0.78 . The alpha coefficient for the entire instrument was 0.79 . Spearman-Brown coefficient obtained was 0.58 while alpha coefficient for the two halves was 0.48 and 0.55 respectively.

\subsection{Procedure}

A pilot study was conducted on 25 students of various departments of the University of Karachi for this study, in which they were shown the big five inventory items and were asked to mark the items they found hard to 
comprehend. Then, they were asked to give alternate explanations for the words they had found hard. This was done in order to assess the language difficulty level of the Big Five Inventory items. Based on the responses obtained, a list of difficult items and their meanings was made which was given at the time of the study to any participant who expressed a difficulty in comprehending the items.

The participants were purposely selected as being call centre agents of banks and telecommunication companies, which were contacted for this study through their HR departments. All the participants belonged to the inbound call centre division as they are the ones facing the most stress and conflict.

\section{Results}

We have attempted to find any correlations among conflict handling styles and personality traits of employees (call centre representatives) in our initial analyses. In subsequent analyses, we have tried to extract a model that exists among call centre representatives. This model may represent any desired or un-desired characteristics (traits and conflict resolution style) that may be utilized by these representatives on day-to-day basis while resolving some conflict.

Looking at the overall correlations (table1), we see significant correlations between openness trait and integrating (0.42r), compromising $(0.34 \mathrm{r})$, obliging $(0.32 \mathrm{r})$, and dominating $(0.23 \mathrm{r})$ style of conflict resolution. Although, openness and dominating style has a significant relationship however, relations were relatively weaker. Similarly, neuroticism shows a significant relationship to avoiding. Conscientiousness depicts significant relation to obliging $(0.37 \mathrm{r})$ and to integrating $(0.35 \mathrm{r})$. Agreeableness agrees with obliging $(0.34 \mathrm{r})$ and integrating $(0.30 \mathrm{r})$. Extraversion was significantly related to compromising $(0.33 \mathrm{r})$ and rightly related to dominating $(0.21 \mathrm{r})$, respectively.

Table 1. Correlations - all employees' scores

\begin{tabular}{llllll}
\hline$[\mathrm{N}=128]$ & Integrating & Obliging & Dominating & Avoiding & Compromising \\
\hline Extraversion & .162 & $.179^{*}$ & $.211^{*}$ & -.122 & $.337^{* *}$ \\
Agreeableness & $.300^{* *}$ & $.342^{* *}$ & -.048 & .097 & .103 \\
Conscientiousness & $.353^{* *}$ & $.373^{* *}$ & .038 & -.014 & .168 \\
Neuroticism & -.032 & -.018 & -.123 & $.212^{*}$ & -.069 \\
Openness & $.427^{* *}$ & $.326^{* *}$ & $.234^{* *}$ & .043 & $.340^{* *}$ \\
\hline
\end{tabular}

These relations display more or less the same pattern, as in overall analysis, when explored separately for banks and telecommunication sectors. In telecom sector (table2), openness trait was related to integrating style of conflict resolution (0.44r). Obliging style was related to openness $(0.42 \mathrm{r})$, and compromising style was related to openness $(0.35 \mathrm{r})$. Dominating was related to openness $(0.26 \mathrm{r})$. Conscientiousness was significantly related to obliging (o.45r), to integrating (0.37r), and to compromising (0.27r). Agreeableness was related to obliging ( $0.46 \mathrm{r})$, to integrating $(0.30 \mathrm{r})$ and to compromising $(0.25 \mathrm{r})$. Extraversion trait was related significantly to obliging $(0.38 \mathrm{r})$, to compromising $((0.35 r)$ and to integrating $(0.28 r)$, respectively.

Table 2. Correlations - telecomm employees' scores

\begin{tabular}{llllll}
\hline$[\mathrm{N}=63]$ & Integrating & Obliging & Dominating & Avoiding & Compromising \\
\hline Extraversion & $.280^{*}$ & $.387^{* *}$ & .214 & -.101 & $.357^{* *}$ \\
Agreeableness & $.305^{*}$ & $.463^{* *}$ & -.129 & .198 & $.257^{*}$ \\
Conscientiousness & $.375^{* *}$ & $.454^{* *}$ & -.005 & .057 & $.277^{*}$ \\
Neuroticism & .016 & -.045 & -.016 & .134 & -.081 \\
Openness & $.441^{* *}$ & $.429^{* *}$ & $.268^{*}$ & .044 & $.351^{* *}$
\end{tabular}

** Correlation is significant at the 0.01 level (2-tailed).

* Correlation is significant at the 0.05 level (2-tailed). 
In bank sector (table3) we observe few differences from overall analysis. Openness trait was equally related to integrity and compromising styles (0.40r), a significant but relatively weaker relationship exists to obliging ( $0.26 \mathrm{r})$ Neuroticism was related to avoiding $(0.28 \mathrm{r})$ and dominating $(0.25 \mathrm{r})$. Conscientiousness was significantly related to integrating (0.32r) and obliging (0.31r). Agreeableness agrees significantly to integrating (0.29r). Similarly, extraversion was significantly related to compromising.

Table 3. Correlations - bank employees' scores

\begin{tabular}{llllll}
\hline$[\mathrm{N}=65]$ & Integrating & Obliging & Dominating & Avoiding & Compromising \\
\hline Extraversion & .044 & -.029 & .206 & -.150 & $.329^{* *}$ \\
Agreeableness & $.295^{*}$ & .207 & .067 & -.001 & -.030 \\
Conscientiousness & $.320^{* *}$ & $.318^{* *}$ & .127 & -.056 & .118 \\
Neuroticism & -.084 & .006 & $-.255^{*}$ & $.289^{*}$ & -.072 \\
Openness & $.402^{* *}$ & $.260^{*}$ & .239 & .085 & $.400^{* *}$ \\
\hline
\end{tabular}

** Correlation is significant at the 0.01 level (2-tailed).

* Correlation is significant at the 0.05 level (2-tailed).

In bank sector among females (table4), integrating style was significantly related to agreeableness $(0.57 \mathrm{r})$, to conscientiousness $(0.56 \mathrm{r})$, and to openness $(0.47 \mathrm{r})$. Obliging style was related conscientiousness $(0.50 \mathrm{r})$, to agreeableness $(0.42 \mathrm{r})$, and to openness $(0.40 \mathrm{r})$. Avoiding style was significantly related to neuroticism $(0.37 \mathrm{r})$. Compromising style was related to openness $(0.43 \mathrm{r})$.

Table 4. Correlations institute $=$ bank, gender $=$ female

\begin{tabular}{llllll}
\hline $\mathrm{N}=28$ & Extraversion & Agreeableness & Conscientiousness & Neuroticism & Openness \\
\hline Integrating & -.032 & $.576^{* *}$ & $.561^{* *}$ & -.045 & $.477^{*}$ \\
Obliging & -.029 & $.421^{*}$ & $.504^{* *}$ & .051 & $.402^{*}$ \\
Dominating & .305 & .171 & .232 & -.281 & .184 \\
Avoiding & -.223 & .158 & .221 & $.374^{*}$ & .182 \\
Compromising & .368 & .104 & .199 & .079 & $.439^{*}$ \\
\hline
\end{tabular}

** Correlation is significant at the 0.01 level (2-tailed).

* Correlation is significant at the 0.05 level (2-tailed).

Among males (table5) in bank sector two styles were related to a single trait, i.e., integrating style was related to openness $(0.45 r)$ and compromising style was again related to openness $(0.32 r)$.

Table 5. Correlations institute $=$ bank, gender $=$ male

\begin{tabular}{llllll}
\hline $\mathrm{N}=37$ & Extraversion & Agreeableness & Conscientiousness & Neuroticism & Openness \\
\hline Integrating & .180 & .189 & .248 & -.169 & $.458^{* *}$ \\
Obliging & .019 & .103 & .210 & -.068 & .167 \\
Dominating & .148 & .025 & .067 & -.253 & .305 \\
Avoiding & -.031 & -.097 & -.197 & .194 & .060 \\
Compromising & .203 & -.022 & .035 & -.092 & $.328^{*}$ \\
\hline
\end{tabular}

** Correlation is significant at the 0.01 level (2-tailed).

* Correlation is significant at the 0.05 level (2-tailed). 
In telecom sector among females (table6) significant relationships were found between openness trait and integrity style of conflict resolution $(0.42 \mathrm{r})$, openness and obliging $(0.55 \mathrm{r})$. Compromising style was related to openness trait $(0.41 \mathrm{r})$ to extraversion $(0.34 \mathrm{r})$.

Table 6 . Correlations institute $=$ telecomm, gender $=$ female

\begin{tabular}{llllll}
\hline $\mathrm{N}=33$ & Extraversion & Agreeableness & Conscientiousness & Neuroticism & Openness \\
\hline Integrating & .060 & -.045 & .210 & .112 & $.428^{*}$ \\
Obliging & .248 & .310 & .317 & -.028 & $.557^{* *}$ \\
Dominating & .180 & -.309 & -.097 & .098 & .223 \\
Avoiding & -.184 & .033 & -.184 & .159 & -.079 \\
Compromising & $.348^{*}$ & .240 & .121 & -.122 & $.419^{*}$ \\
\hline
\end{tabular}

** Correlation is significant at the 0.01 level (2-tailed).

* Correlation is significant at the 0.05 level (2-tailed).

Among males in telecom sector (table7), integrating style of conflict resolution was related to conscientiousness trait $(0.59 \mathrm{r})$, to agreeableness $(0.54 \mathrm{r})$, to extraversion $(0.47 \mathrm{r})$, and to openness $(0.45 \mathrm{r})$. Obliging style was related to conscientiousness $(0.62 \mathrm{r})$, to agreeableness $(0.48 \mathrm{r})$, and to extraversion $((0.46 \mathrm{r})$.

Table 7. Correlations institute $=$ correlations telecomm, gender $=$ male

\begin{tabular}{llllll}
\hline $\mathrm{N}=30$ & Extraversion & Agreeableness & Conscientiousness & Neuroticism & Openness \\
\hline Integrating & $.475^{* *}$ & $.547^{* *}$ & $.591^{* *}$ & -.270 & $.457^{*}$ \\
Obliging & $.465^{* *}$ & $.484^{* *}$ & $.626^{* *}$ & -.306 & $.365^{*}$ \\
Dominating & .326 & .137 & .196 & -.121 & $.377^{*}$ \\
Avoiding & -.075 & .261 & .360 & -.068 & .164 \\
Compromising & .346 & .220 & $.438^{*}$ & -.175 & .296 \\
\hline
\end{tabular}

** Correlation is significant at the 0.01 level (2-tailed).

* Correlation is significant at the 0.05 level (2-tailed).

Conclusively, three, conflict handling/resolution style and three personality traits were determined through all the analyses on correlations. Among conflict handling styles first most occurring style was integrating, the second most occurring style was obliging, and third most occurring style was compromising. Among personality traits the most occurring traits was openness, second most occurring trait was conscientiousness, and third most occurring trait was agreeableness.

To establish that the correlated factors (traits \& styles) were the players in these scenarios, factor analysis, using principal axis factoring, was conducted. KMO and Bartlett's test tells about the suitability of the data to conduct the factor analysis. Table (8), shows that the data is suitable (KMO: 0.73) for factor analysis. The table displays factor loadings when factor analysis was conducted on 10 factors (traits-conflict handling styles combined). Same factors were loaded in factor analysis. However, theoretical connotations of these factors were questionable. The trait is this questionable area was neuroticism and conflict handling style area were dominating and avoiding. 
Table 8. KMO \& Bartlett's test and factor loadings KMO and Bartlett's test

\begin{tabular}{lll}
\hline Kaiser-Meyer-Olkin Measure of Sampling Adequacy & .733 \\
\hline Bartlett's Test of Sphericity & $\begin{array}{l}\text { Approx. Chi-Square } \\
\text { df }\end{array}$ & 317.656 \\
& Sig. & 45 \\
Factor Loadings & & .000 \\
Extraversion & 0.581 & \\
Agreeableness & 0.646 & \\
Conscientiousness & 0.748 & \\
Neuroticism & -0.442 & \\
Openness & 0.679 & \\
Integrating & 0.653 & \\
Obliging & 0.656 & \\
Dominating & 0.320 \\
Avoiding & 0.100 \\
Compromising & 0.522 \\
\hline
\end{tabular}

This paved the way for the extraction and appraisal of some existing services model where the call centre representatives may utilize these factors. This model simulation was conducted through SEM.

The first model simulation includes all the factors in both sectors (bank \& telecom). Results (figure 1, table 9) show some interesting patterns along with extracted factors similar to previous analyses. Regression weights (rw) suggest the utilization of the factors within the service area by the call centre representatives. Obliging (rw: 0.79), integrating (rw: 0.71), compromising (rw: 0.43), dominating (rw: 0.26), neuroticism (rw: -.05). This fifth extracted factor i.e., neuroticism's negativity suggests that the factor is not related to the model, but it establishes its necessity for the convergence of the model.

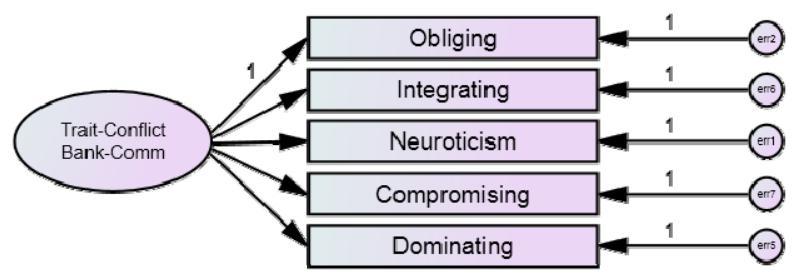

Figure 1. Model 1: all sectors and all factors

Table 9. Model 1: all sectors and all factors

\begin{tabular}{lllllll}
\hline$\Pi^{2}$ & $\mathbf{P}$ & GFI & AGFI & TLI & CFI & RMSEA \\
\hline 6.34 & 0.27 & 0.98 & 0.94 & 0.96 & 0.98 & 0.04 \\
\hline
\end{tabular}

In the bank sector alone, the converging model (figure 2, table 10) suggests four factors, i.e., integrating (rw: 0.88), obliging (rw: 0.69), compromising (rw: 0.16), however, the fourth extracted factor, i.e., neuroticism's negativity 
(rw: -0.07) suggests that the factor is not related to the model, but it establishes its necessity for the convergence of the model.

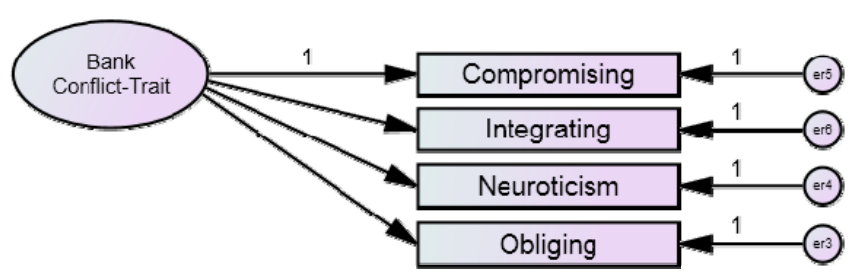

Figure 2. Model 2: bank sector and all factors

Table 10. Model: Bank sector and all factors

\begin{tabular}{lllllll}
\hline$\Pi^{\mathbf{2}}$ & $\mathbf{P}$ & GFI & AGFI & TLI & CFI & RMSEA \\
\hline 0.85 & 0.65 & 0.99 & 0.96 & 1.00 & 1.00 & 0.00 \\
\hline
\end{tabular}

In telecommunication sector alone, the converging model (figure 3, table 11) suggests five factors i.e., obliging (rw: 0.81), compromising (rw: 0.71), integrating (rw: 0.68), dominating (rw:-0.12), and neuroticism (rw:-.5). here again the negativity suggests that the factor is not related to the model, but it establishes its necessity for the convergence of the model.

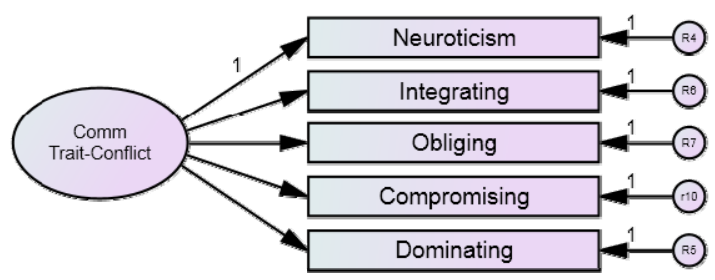

Figure 3. Model 3: telecom sector and all factors

Table 11. Model: Telecom sector and all factors

\begin{tabular}{lllllll}
\hline$\Pi^{2}$ & $\mathbf{P}$ & GFI & AGFI & TLI & CFI & RMSEA \\
\hline 1.00 & 0.96 & 0.99 & 0.98 & 1.00 & 1.00 & 0.00 \\
\hline
\end{tabular}

\section{Discussion}

We face situations when we have to deal with conflicts. The resolution of all conflicts depend upon our problem solving style that is in retrospect depends on our personality traits that make the real of us. However, there are situations where we need special trainings to decipher the situation to understand the nature of conflict and use techniques that are required in such situations. This may ask us to learn and train ourselves to cope with our own temperaments. This is especially true in service-oriented businesses.

In this particular research, we have attempted to determine the relationship among personality traits and conflict handling style of those people who work as representatives at call centers. Two pertinent business areas were selected, i.e., bank and telecommunication. Call centers (customer facilitation) associated to these two sectors are among the busiest centers. Representatives working in these environments receive services requests, SOS calls, complaints, and threats. Therefore, they have to utilize some desirable and undesirable fashion to entertain these calls.

This is why, along with the determination of any relationship among personality traits and conflict handling style it was legitimate to try to extract the existing services model that these representatives utilize on daily basis. We 
assumed that this model might include some traits and conflict handling styles that are not suitable for a call centre representative according to the laws of service marketing.

In the first phase of analyses, we run a set of co-relational statistics to find the relationships among traits and styles. The first personality trait for BFI, openness was found related to four conflict handling styles i.e., integrating, compromising, obliging, and dominating respectively. Apropos conflict handling style scale it makes sense that if a person is high on openness to experience s/he will find it easy to integrate and compromise with people however, obliging is as well associated to openness but it is more of a requirement of marketing strategy. At some point of time when corporate decisions must be followed whether someone likes them or not, these corporate ambassadors (representatives) must dominate the situation to assert the organizational rule. This phenomenon is clearer in the relationship between neuroticism trait and avoiding style of conflict handling. The bizarre approach of a neurotic person makes it handy for this person to avoid any situation requiring problem solving or if one is compelled to indulge in such situation her/his performance will never be up to mark. Similarly, the relationship between extraversion and compromising and dominating suggests that it is easy for extravert to be dominant in a bilateral situation and on the contrary, it is one's learning to compromise at the same moment.

Similar patterns were found in analyses when run on separate sectors, however, few differences were found like in telecom sector neuroticism was altogether missing i.e., never relating to any of the conflict handling styles significantly. In bank, it is relating to avoiding like the previous, overall, analysis. In the analyses on gender basis, females working in bank, show neuroticism trait, however, it was not evident in any other scenario. There might be several reasons for this particular result as if the comprehension of the service style in banks by the females is not accurate, lack of training, or may be the wrong selection of personnel for this particular job.

Our data was suitable for the factor analysis according to KMO \& Bartlett's test of Sphericity. KMO index that ranges from 0 to 1 , and indicates that KMO more than 0.50 are considered appropriate for factor analysis (Pallant 2001) The factor analysis depicts that all the constituent factors except avoiding in conflict handling style, whether correlating significantly or do not correlating, have relatively strong loadings.

In the last round of analyses, structural equation modeling was run with maximum likelihood. Three permutations i.e., all sectors (bank \& telecom) with all factors (traits \& styles), all factors in bank situation, and all factors in telecom situation, were run to extract existing model.

The first converging model includes five factors with reasonable regression weights. Model was scrutinized on six cutoff scores (fit indices: chi square, GFI, AGFI, TLI, CFI, and RMSEA) and all the scores suggest that the model is a good fit. The extracted factors are obliging, integrating, neuroticism, compromising, and dominating. We have already discussed the individual importance of traits and conflict handing styles however, the presence of neuroticism trait, with a reasonably strong regression weight, on the conversing model, model does not converge without this factor, puts a question marks on training being provided to individuals prior inducting them in any one of the services sectors. The negativity of the factor on the model suggests that this is not the part of the model however, looking from another perspective we can decipher that the model might be suggesting that the neuroticism is merely undesirable and shouldn't be the part of service model.

Similar results were found when models were extracted within the particular sectors. Neuroticism was the integral part of all the converging models. In bank, model misses the dominating style of conflict resolution. This might be the cause of having avoiding style in females working in banks as they do not like to or may not dominate the situation and this prominent in the results because more females work in banks at public service counters facilitation centers (call centers) and according to national statistics. Neuroticism trait is evident in all permutations, strongly suggesting some lack of understanding on the part of call center representatives who were supposed to work according to the established rules of service or facilitation model.

\subsection{Implications}

Specialized Training modules for people to work in emotionally charged environments are necessary. These emotional laborers lack the fundamental understanding of emotional exchange in communications. Neuroticism is an undesirable trait for call-centre-representative-candidate, however, our results depict that it is unnecessarily present in all converging models. This shows that the basic training programs do not prepare call centre representatives to cope with their impulses. They do not understand how to use a mix of emotions and communications techniques in situations where conflicts arise.

We strongly recommend the overhaul of the training modules being utilized at institutes associated to train people to work as call center representatives. We think a psychological profiling and persona problem solving styles must be considered prior inducting an individual into training. The training module must contain some learning about 
human behavior and communication skills apropos human need, moreover, knowing and understanding oneself is necessary to control impulses that are undesirable in such situations.

\section{References}

Aksin Z., Armony M., \& Vijay M. (2007). The Modern Call Center: A Multi-Disciplinary Perspective on Operations Management Research. Production and Operations Management, 16(6), 665-688. http://dx.doi.org/10.1111/j.1937-5956.2007.tb00288.x

Blake, R. R., \& Mouton, J. S. (1964). The managerial grid. Houston, TX: Gulf.

Evenson, Harker \& Frei. (1999). Retreived from http://www.hbs.edu/research/facpubs/workingpapers/papers2/9899/99-110.pdf

Fossati A., Borroni S., Marchione D., \& Maffei, C. (2011). The Big Five Inventory (BFI): Reliability and validity of its Italian translation in three independent nonclinical samples. European Journal of Psychological Assessment, 27(1), 50-58. http://dx.doi.org/10.1027/1015-5759/a000043

Jameson, J. K. (1999). Toward a comprehensive model for the assessment and management of intra-organizational conflict: Developing the framework. International Journal of Conflict Management, 10, 268-294. http://dx.doi.org/10.1108/eb022827

John, O. P., \& Srivastava, S. (1999). The Big Five trait taxonomy: History, measurement, and theoretical perspectives. In L. A. Pervin \& O. P. John (Eds.), Handbook of personality theory and research (pp. 102-138). New York: Guilford Press.

Liu, A., \& Zhai, X. (2011). Influences of Personality on the Adoption of Conflict-Handling Styles and Conflict Outcomes for Facility Managers. Journal of Legal Affairs and Dispute Resolution in Engineering and Construction, 3(SPECIAL ISSUE: Construction Dispute Negotiation), 101-108. http://dx.doi.org/10.1061/(ASCE)LA.1943-4170.0000056

Olukemi O. S., Shanthi S., \& Sijun W. (2009). Call center employee personality factors and service performance. Journal of Services Marketing, 23(5), 301-317. http://dx.doi.org/10.1108/08876040910973413

Pallant, J. (2001). SPSS survival manual: a step by step guide to data analysis using spss for windows (version 10). Maryborough, Victoria, Australia: McPherson's Printing Group.

Rahim, M. A. (1983a). Rahim organizational conflict inventories: Professional manual. Palo Alto, CA: Consulting Psychologists Press.

Rahim, M. A. (1983b). A measure of styles of handling interpersonal conflict. Academy of Management Journal, 26, 368-376. http://dx.doi.org/10.2307/255985

Rahim, M. A. (2001). Managing Conflict in Organizations. Westpart, CT. USA: Quorum Books.

Rahim, M. A. (2002). Toward a theory of managing organizational conflict. The International Journal of Conflict Management, 13(3), 206-235. http://dx.doi.org/10.1108/eb022874

Rahim M. A., Antonioni D., \& Psenicka C. (2001). A Structural Equations Model of Leader Power, Subordinates' Styles of Handling Conflict, and Job Performance. International Journal of Conflict Management, 12(3), 191-211. http://dx.doi.org/10.1108/eb022855

Stone, F. (1999). How to resolve conflicts at work. New York: AMACOM.

Wall, J. A., \& Callister, R. R. (1995). Conflict and its management. Journal of management, 21, 515-558. 